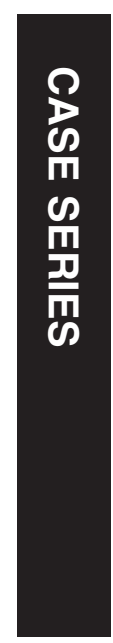

\title{
Medical therapy for uveal effusion syndrome
}

\begin{abstract}
Purpose To report a case series of three patients with bilateral uveal effusion syndrome (UES), treated conservatively with oral carbonic anhydrase inhibitors and topical prostaglandin analogues (PAs). Methods Three patients with bilateral UES were treated with the same initial therapy. Topical PA latanoprost $0.005 \%$ and acetazolamide $250 \mathrm{mg}$ were administered in order to reduce intraocular pressure, improve uveoscleral outflow, and facilitate resolution of uveal effusion.

Results The chorioretinal detachment resolved within 3 months in two reported patients while the third one underwent surgery on his left eye. After clinical improvement, further oral therapy with acetazolamide was stopped, while topical prostaglandins were continued for at least the next 3 months. All patients were free from recurrence during the follow-up period. Conclusion Although the usually recommended UES therapy is partial or full-thickness sclerectomy, our case series showed apparent resolution of chorioretinal detachment in two patients on medical therapy alone. Conservative therapy may be the first step before the standard recommended surgical approach, but further studies are needed to verify the effectiveness of reported therapy. Eye (2014) 28, 1028-1031; doi:10.1038/eye.2014.126; published online 6 June 2014
\end{abstract}

BA Derk, University Clinical Centre 'Sestre milosrdnice', University Department of Ophthalmology,

Vinogradska 29, 10000

Zagreb, Croatia

Tel: + 38513787 106;

Fax: + 38513787359 .

E-mail: biljana.andrijevic@ zg.htnet.hr

Received: 13 March 2013 Accepted in revised form: 28 April 2014

Published online:

6 June 2014
B Andrijević Derk 1 , G Benčić 1 , V Ćorluka ${ }^{2}$ M Zorić Geber ${ }^{1}$ and Z Vatavuk ${ }^{1}$
The suggested therapy according to Gass ${ }^{5}$ and Jackson et $a l^{6}$ is partial or full-thickness sclerectomy or sclerotomy with mytomycin C. ${ }^{7}$

Medical therapy for UES with long-term oral NSAIDs has been described with variable results. ${ }^{8}$ Prostaglandin analogues (PAs) have been shown to increase uveoscleral outflow by increasing scleral permeability, ${ }^{9}$ and have been used postoperatively to treat UES with equivocal benefit in one patient, ${ }^{10}$ but they have not previously been reported as a primary treatment.

This article presents a case series of three patients with UES, treated with topical PA and oral carbonic anhydrase inhibitor.

\section{Case reports}

Patients with UES were referred to our hospital as a consecutive series from October 2010 to September 2011. All three cases had painless, gradual loss of vision with a bilateral peripheral chorioretinal detachment, discrete macular choroidal folds, and subretinal fluid (Figures 1a-d).

To rule out all possible inflammatory and hydrostatic causes of uveal effusion, we conducted thorough ophthalmological, internal, and neurological examination, including MRI of the brain and orbit with measurement of scleral thickness in all three cases. The MRI T1-weighted image of scleral thickness is shown in Figure 2.

Relevant clinical data including bestcorrected visual acuity, refractive status, intraocular pressure, axial length, scleral thickness, central foveal thickness, final visual acuity, and follow-up period of all three reported cases are shown in Table 1.

We opted to treat Case 1 empirically ('off-label' use) with latanoprost $0.005 \%$ once a day and oral acetazolamide $250 \mathrm{mg}$ twice a day. Chorioretinal re-attachment and improvement in vision was achieved in both eyes after 3 months of therapy, so we discontinued acetazolamide, leaving the patient only 

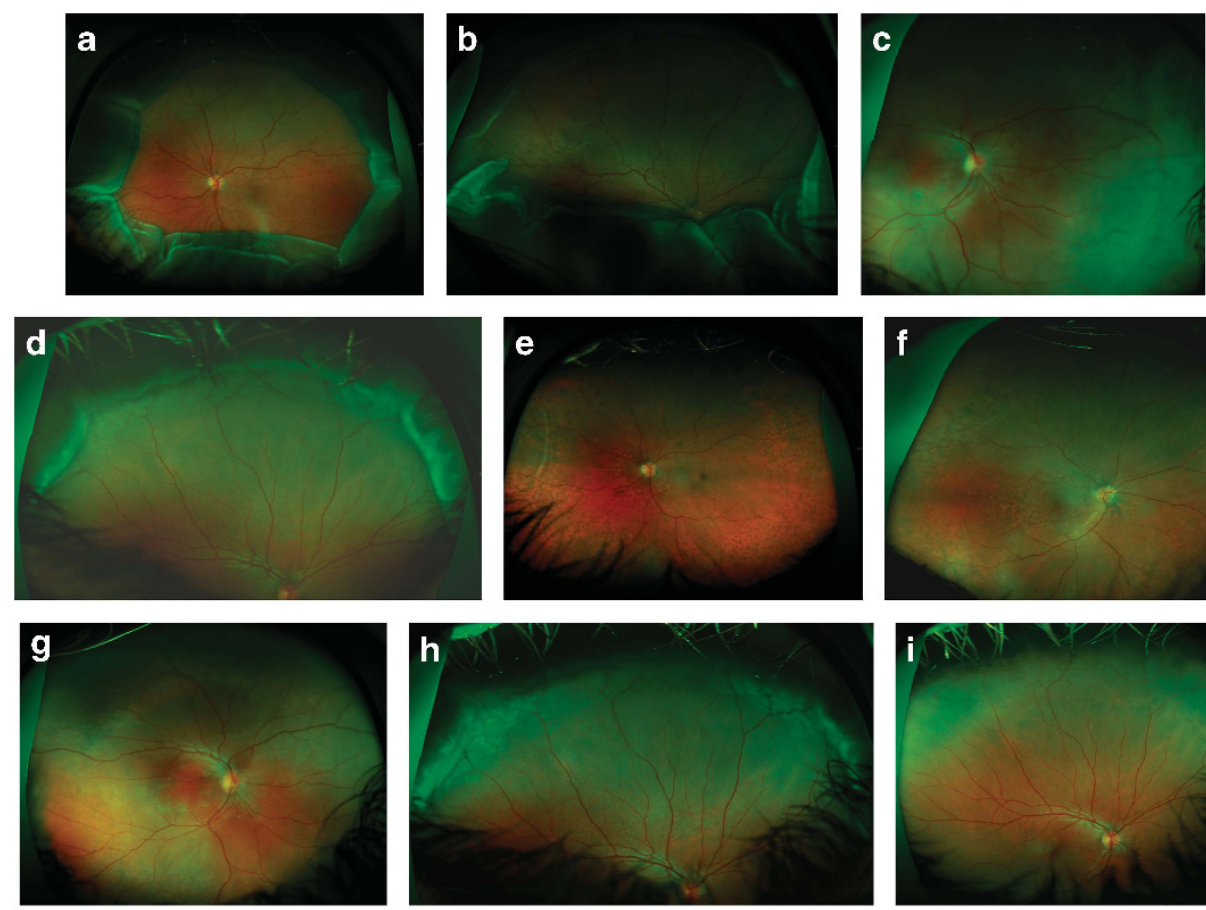
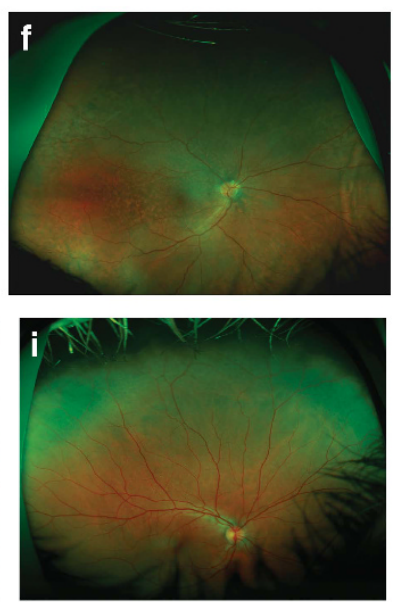

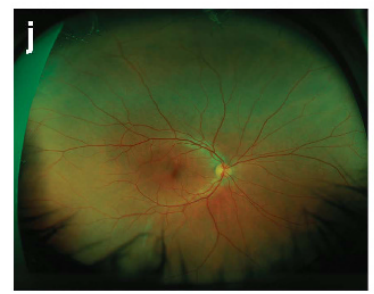

Figure 1 Case 1: (a, b) Wide-field fundus image of chorioretinal detachment in $360^{\circ}$ of the left eye (LE) and right eye (RE). (e, f) Fundus of LE and RE 12 months after therapy. Note the multiple pigmentary changes throughout the fundus periphery (leopard spots). Case 2: (c) Image of RE uveal effusion. (g) RE six months after the therapy. Case 3: (d) Image of the upper part of RE with uveal effusion. (h) After 3 months of therapy with incomplete UES resolution. (i, j) Upper and central parts of RE after 13 months with complete UES resolution.

on topical latanoprost therapy through the follow-up period. Twelve months after clinical resolution, no recurrence of the effusion was observed (Figures 1e and f).

The same therapy was used for three months in Cases 2 and 3 as we reported in the previous case.

In Case 2, the chorioretinal detachment resolved completely in the right eye (RE) after 3 months and partially in the left eye (LE). We discontinued acetazolamide therapy, leaving only topical latanoprost therapy for RE for the next 3 months and performed partial sclerectomy in the inferior temporal and nasal quadrants of the LE. Six months after the procedure both eyes showed no signs of disease recurrence (Figure $1 \mathrm{~g}$ ).

After the same initial therapy, Case 3 showed incomplete improvement in clinical findings (Figure 1h), so we continued with topical prostaglandin therapy for the next 13 months (Figures $1 \mathrm{i}$ and j).

\section{Discussion}

The standard and recommended therapy for UES is surgery. ${ }^{5-7}$ Medical treatment using NSAIDs has been described with rare success. ${ }^{8}$ PAs are known to enhance scleral macromolecular permeability. ${ }^{9}$ Recently, Jackson et $a l^{10}$ revealed that UES can be associated with reduced transscleral albumin permeability.

Moldow et $a l^{11}$ reported that acetazolamide affects the blood retinal barrier cells with stimulation of at least one pump mechanism. The authors presumed that other transport systems are affected too, but it could not have been determined by that study. Although acetazolamide reduced the initial levels of intraocular pressure by its inhibition effect on aqueous production, the impact on other cell transport mechanisms, as much as acetazolamide's impact on choroidal circulation, could contribute to the positive clinical response in UES patients. The treatment used in our report combined 
Table 1 Clinical data of patients with uveal effusion syndrome (UES)

\begin{tabular}{|c|c|c|c|c|c|c|c|c|}
\hline & $\begin{array}{l}\text { Age/gender } \\
\text { (years/F, } M)\end{array}$ & $\begin{array}{c}\text { Refractive error/BCVA } \\
(\mathrm{D} / \text { Snellen op })\end{array}$ & $\begin{array}{c}I O P \\
(m m H g)\end{array}$ & $\begin{array}{l}\text { Macular OCT- } \\
\text { CFT }(\mu \mathrm{m})\end{array}$ & $\begin{array}{c}\text { Biometry } A L \\
(\mathrm{~mm})\end{array}$ & $\begin{array}{l}\text { MRIST } \\
(\mathrm{mm})\end{array}$ & $\begin{array}{l}\text { Final BCVA } \\
\text { (Snellen op.) }\end{array}$ & $\begin{array}{l}\text { Follow-up period } \\
\text { (months) }\end{array}$ \\
\hline \multirow[t]{2}{*}{ Case 1} & \multirow[t]{2}{*}{$43 / F$} & $+13.0 D=0.05$ & 26 & 558 & 15.8 & 1.7 & 0.5 & \multirow{2}{*}{15} \\
\hline & & $+13.0 D=0.05$ & 28 & 841 & 15.7 & 1.5 & 0.1 & \\
\hline \multirow[t]{2}{*}{ Case 2} & \multirow[t]{2}{*}{$53 / \mathrm{M}$} & $+6.0 D=0.5$ & 16 & 261 & 21.17 & 1.9 & 0.8 & \multirow{2}{*}{9} \\
\hline & & $+8.0 D=0.6$ & 15 & 303 & 21.07 & 1.5 & 1.0 & \\
\hline \multirow[t]{2}{*}{ Case 3} & \multirow[t]{2}{*}{$48 / \mathrm{M}$} & R Sc. $=1.0$ (blurred) & 12 & 380 & 22.01 & 1.9 & 1.0 & \multirow{2}{*}{16} \\
\hline & & Sc. $=1.0$ & 12 & 310 & 22.13 & 1.9 & 1.0 & \\
\hline
\end{tabular}

Abbreviations: AL, axial length (measured by IOL master); BCVA, best-corrected visual acuity; CFT, central foveolar thickness; F/M, female/male; IOP, intraocular pressure; L, left eye; MRI, magnetic resonance imaging; op., optotype; R, right eye; Sc., without correction; ST, scleral thickness.

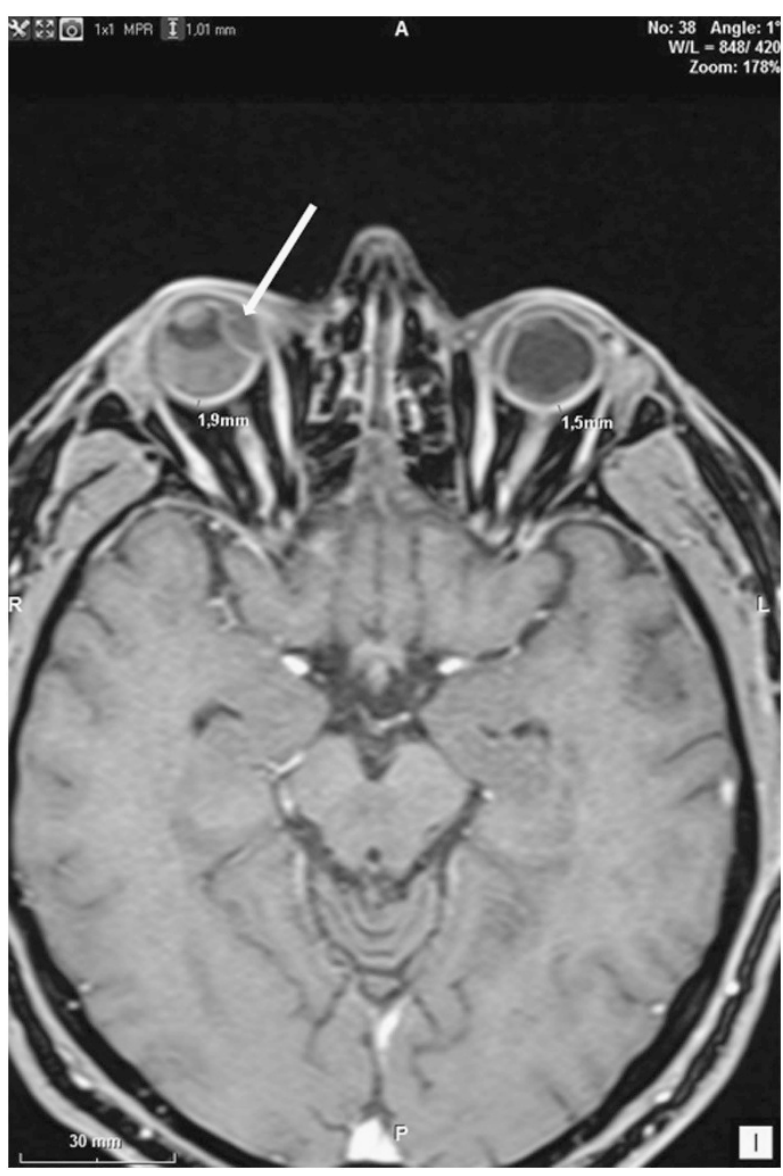

Figure 2 MRI scan (T1-weighted images with gadoterate meglumine contrast) showing an increased scleral thickness in both eyes of Case 2; note the chorioretinal detachment in the right eye (arrow).

effects of PAs on scleral permeability and acetazolamide edema-reducing effects due to stimulation of ion and fluid removal. We cannot discriminate which of these two medications, or even whether the natural history of the disease, is responsible for the beneficial final outcome, but the effusion resolved completely in two patients with therapy only, while the third patient needed surgery for the LE. In all three patients scleral thickness was significantly increased compared to normal values. ${ }^{12}$

In conclusion, conservative therapy for UES can be the first therapeutic step prior to surgical intervention. Because UES is a rare condition, it is unlikely that a clinical trial comparing different treatments is feasible at this time, but further case-series studies with UES patients are needed to determine the safety and effectiveness of this therapy.

\section{Summary}

What was known before

- The recommended and standard therapy for uveal effusion syndrome was surgical procedure.

What this study adds

- We have shown that medical therapy can be the first-step choice in the treatment of this rare disease and that it may obviate the need for surgery.

\section{Conflict of interest}

The authors declare no conflict of interest.

\section{References}

1 Elagouz M, Stanescu-Segall D, Jackson TL. Uveal effusion syndrome. Surv Ophthalmol 2010; 55: 134-145.

2 Allen KM, Meyers SM, Zegarra H. Nanophthalmic uveal effusion. Retina 1988; 8(2): 145-147.

3 Brockhurst RJ. Nanophthalmos with uveal effusion: a new clinical entity. Arch Ophthalmol 1988; 93: 1289-1299.

4 Schepens CL, Brockhurst RJ. Uveal effusion. I. Clinical picture. Arch Ophthalmol 1963; 70: 189-201.

5 Gass JDM. Uveal effusion syndrome: a new hypothesis concerning pathogenesis and technique of surgical treatment. Retina 1983; 3: 159-163.

6 Jackson TL, Hussain A, Morley AMS, Sullivan PM, Hodgetts A, El-Osta A et al. Scleral hydraulic conductivity and macromolecular diffusion in patients with uveal effusion syndrome. Invest Ophthalmol Vis Sci 2008; 49: 5033-5040. 
7 Suzuki Y, Nishina S, Azuma N. Scleral window surgery and topical mitomycin $\mathrm{C}$ for nanophthalmic uveal effusion complicated by renal failure. Graefe's Arch Clin Exp Ophthalmol 2007; 245: 755-757.

8 Kumar A, Kedar S, Singh RP. The indocyanine green findings in idiopathic uveal effusion syndrome. Indian J Ophthalmol 2002; 50: 217-219.

9 Weinreb RN. Enhacement of scleral macromolecular permeability with prostaglandins. Trans Am Ophthalmol Soc 2001; 99: 319-343.
10 Jackson TL, Hussain A, Salisbury J, Sherwood R, Sullivan PM, Marshall J. Transscleral albumin diffusion and suprachoroidal albumin concentration in uveal effusion syndrome. Retina 2012; 32: 177-182.

11 Moldow B, Sander B, Larsen M, Lund-Andersen H. Effects of Acetazolamide on passive and active transport of fluorescein across the normal BRB. Invest Ophthalmol Vis Sci 1999; 40: 1770-1775.

12 Vurgese S, Panda Jonas S, Jonas JB. Scleral thickness in human eyes. PLoS One 2012; 7(1): e29692. 